\title{
Overexpression of discoidin domain receptor 1 increases the migration and invasion of hepatocellular carcinoma cells in association with matrix metalloproteinase
}

\author{
HO SUNG PARK ${ }^{1}$, KYUNG RYOUL KIM ${ }^{1}$, HO JIN LEE ${ }^{1}$, HA NA CHOI $^{1}$, \\ DAE KI KIM ${ }^{2}$, BEOM TAE KIM ${ }^{3}$ and WOO SUNG MOON ${ }^{1}$
}

Departments of ${ }^{1}$ Pathology, ${ }^{2}$ Immunology, Medical School and Institute for Medical Science, ${ }^{3}$ Research Center of
Bioactive Materials, College of Natural Science, Chonbuk National University, Jeonju 561-180, Korea

Received June 3, 2007; Accepted August 16, 2007

\begin{abstract}
The discoidin domain receptor (DDR) is a class of receptor tyrosine kinases that binds to several collagens. DDR1 is widely expressed in fast-growing invasive tumors of the breast, ovary, esophagus, brain and lung. However, there is little information on the expression of DDR1 in hepatocellular carcinoma (HCC) or its function in migration and invasion. Western blot analysis was performed to determine if four HCC cell lines (HLE, Huh-7, HepG2 and SH-J1) express DDR1. The HLE and Huh-7 cell lines were transfected with two isoforms of DDR1, DDR1a and DDR1b. Immunoprecipitation for DDR1 was then performed. Migration and invasion assays were carried out and the number of migrating cells was counted in 6 randomly selected fields per well under an optical microscope. Zymography was used to determine the level of the matrix metalloproteinase (MMP)-2 and -9 expression. DDR1 was expressed in all four cell lines. In the migration assay, the number of migrating cells was significantly higher in the DDR1a- or DDR1b-overexpressing HLE and Huh-7 cells, particularly after collagen type I stimulation $(\mathrm{P}<0.001)$. Collagen type I stimulation activated DDR1. In the invasion assay, there was a significantly higher number of invading cells in the DDR1a- or DDR1boverexpressing HLE cells and DDR1a-overexpressing Huh-7 cells than in the control $(\mathrm{P}<0.01)$. The DDR1a- and DDR1boverexpressing HLE cells showed a remarkable increase in the MMP-9 and -2 expression, particularly the active MMP-2. The DDR1a- and DDR1b-overexpressing Huh-7 cells showed a slight increase in the MMP-9 and -2 expression. The
\end{abstract}

Correspondence to: Dr Woo Sung Moon, Department of Pathology, Chonbuk National University Medical School, San 2-20 Geumamdong, Deokjin-gu, Jeonju 561-180, Korea

E-mail:mws@chonbuk.ac.kr

Key words: carcinoma, hepatocellular, discoidin domain receptor1 protein, human, matrix metalloproteinase 2, matrix metalloproteinase 9 increased invasiveness of the HCC may be associated with the overexpression of either DDR1a or DDR1b mediated by MMP-2 and -9. Although this study provided one possible mechanism for the invasion of HCC cells, more studies are needed to understand the signal through which DDR1a and DDR1b act in invasion.

\section{Introduction}

Hepatocellular carcinoma (HCC) is the sixth most common cancer worldwide in terms of the number of cases but the third most common cause of death from cancer on account of its very poor prognosis (1). The overall median survival of untreated $\mathrm{HCC}$ is $\sim 8$ months and the overall 5-year survival rate is $\sim 5 \%$ (2). The severity of the clinical outcome depends on the invasiveness of the primary $\mathrm{HCC}$, leading to a high rate of intrahepatic recurrence after treatment. Although knowledge of the pathogenesis of tumor progression and metastasis of HCC can help in predicting the prognosis and in making decisions on the appropriate treatment, the molecular mechanisms through which HCC acquires its invasive potential are not completely understood.

The discoidin domain receptor (DDR) is a novel class of receptor tyrosine kinase (RTK) that is characterized by a 155amino acid discoidin homology domain in the extracellular region. The DDR family consists of two members: DDR1 and DDR2 (3). As a result of alternative splicing, 5 DDR1 isoforms were identified (DDR1a-e) (4,5). DDR1 is expressed during embryogenic development and in normal adult epithelial cells of the lung, kidney, colon and brain (4). The targeted deletion of the DDR1 gene in mice resulted in severe defects in placental implantation and mammary gland development (6), suggesting potential roles in the migration and matrix degradation of this receptor. Notably, the overexpression of DDR1 was detected in human cancers of the breast (7), ovary (8), esophagus (9) and brain (10) suggesting that it may play a role in the progression of certain carcinomas. DDR1 is activated by collagen types I, II, III, IV, V and VIII but particularly by collagen types I and III (11). Collagen binding can induce the autophosphorylation of DDR1 (12). However, there is relatively little information on the DDR downstream signaling pathways or functions. 
The ability of malignant cells to penetrate the tissue barriers requires the breakdown of the extracellular matrix, which is mediated by a variety of proteases (13). Proteolytic extracellular matrix (ECM) degradation is an important step in tumor invasion and metastasis. However, various proteinases are involved in this process; matrix metalloproteinase (MMP) can degrade the ECM components and is believed to play a major role in invasion and metastasis. It was reported that an increased MMP expression is correlated with an invasion in various human malignant tumors (14-16). Most clinical data indicate a correlation between the MMP expression and advanced tumor stages, invasion, metastasis and shortened survival. Among the MMPs, MMP-2 and -9 are considered to be particularly important in malignant behavior and there are some reports showing that the overexpression of MMP-2, -3 or -9 is associated with the invasion and metastasis of HCC (17-19).

It is not known if HCC cells express DDR1. Moreover, the potential role of DDR1 in HCC cell lines is unclear, while the relationship between the overexpression of DDR1 and the expression of MMP in HCC has also not been clarified. The aim of this study was to determine if DDR1 is present in HCC cell lines, to clarify the effects of DDR1 on the migration and invasion of HCC cell lines and to identify the relationship between the overexpression of DDR1 and expression of MMP.

\section{Materials and methods}

Cells and cell culture. Four human HCC cell lines (HLE, Huh-7, HepG2 and SH-J1) were used in this study. HLE and Huh-7 were purchased from the Health Science Research Resources Bank (Osaka, Japan) and HepG2 was purchased from the American Type Culture Collection (Manassas, VA). In addition, the sarcomatoid HCC cell line, which is designated as SH-J1, was established in our laboratory (20). The HepG2, HLE and Huh-7 cell lines were cultured according to the cell bank's instructions. The HCC cells were maintained in Dulbecco's modified Eagle's medium (DMEM) and supplemented with penicillin and streptomycin $(100 \mathrm{U} / \mathrm{ml})$ with $10 \%$ fetal bovine serum (Gibco BRL, Gaithersburg, MD) and were grown at $37^{\circ} \mathrm{C}$ in a humidified, $5 \% \mathrm{CO}_{2}$ atmosphere. After $24 \mathrm{~h}$, cultures of $40-60 \%$ confluent cells were used in this study.

Cell transfection. The $3.1 \mathrm{~kb}$ EcoRI-XhoI fragment of DDR1a cDNA and $3.55 \mathrm{~kb}$ EcoRI-BamH1 fragment of DDR1b cDNA were cloned to the plasmid pRK5 (BD Biosciences, Franklin Lakes, NJ). HLE and Huh-7 cells were transiently transfected with the plasmids harboring DDR1a, DDR1b, or the vector only (mock-transduced) using Lipofectin (Invitrogen, Carlsbad, CA). Briefly, one day before transfection, the cells were plated in a $60-\mathrm{mm}$ dish with antibioticfree serum. At the time of tranfection, the cell confluence was $50 \%$ and the medium was changed to a serum-free medium. The DNA for DDR1a and DDR1b ( $2 \mu \mathrm{g}$, respectively) was diluted in $100 \mu 1$ of DMEM. After $15 \mu 1$ of Lipofectin was diluted to $100 \mu 1$ with DMEM, it was left to stand at room temperature for $45 \mathrm{~min}$. The diluted DNA was combined with the diluted Lipofectin. Subsequently, the mixture was incubated for $15 \mathrm{~min}$ at room temperature and added to the cells removed from the growth medium. The cells were incubated at $37^{\circ} \mathrm{C}$ in a $\mathrm{CO}_{2}$ incubator for $18 \mathrm{~h}$. After $44 \mathrm{~h}$, the cells were harvested and the expression of the transgene was evaluated by Western blotting.

Western blotting. The level of DDR1 expression in the four different human HCC cell lines, HepG2, HLE, Huh-7 and $\mathrm{SH}-\mathrm{J} 1$, was examined by Western blotting. Briefly, the adherent cells were lysed in a medium containing $1 \%$ Nonidet P-40 buffer containing $50 \mathrm{mM}$ Tris- $\mathrm{HCl}(\mathrm{pH} 7.4), 150 \mathrm{mM}$ $\mathrm{NaCl}$ and $1 \mathrm{mM}$ EDTA, supplemented with protease inhibitor cocktail (Sigma, St. Louis, MO) and phosphatase inhibitor cocktail I and II (Sigma). Equal amounts of the protein were subjected to $6 \%$ SDS-polyacrylamide gel electrophoresis (SDS-PAGE), transferred to polyvinylidene difluoride (PVDF) membranes (Bio-Rad, Richmond, CA) and then incubated with the DDR1 polyclonal antibody to the carboxyterminus (C-20, Santa Cruz Biotechnology, Santa Cruz, CA) overnight at $4^{\circ} \mathrm{C}$. The bands were visualized using an enhanced chemiluminescence (ECL) system (Amersham Bioscience, Buckinghamshire, UK). The membranes were stripped and reprobed with the anti-actin antibody (Sigma) to confirm equal loading. A luminescent image analyzer (LAS-3000, Fuji Photo Film, Tokyo, Japan) was used to quantify the data.

Immunoprecipitation for DDR1 phosphorylation. After incubating the transfected cells in the collagen type I (30 $\mu \mathrm{g}$ / $\mathrm{ml}$ )-coated dish, the cell lysates were prepared in a RIPA buffer and immunoprecipitation was performed by incubating $0.5 \mathrm{mg}$ of the cell extracts with the DDR1 (C-20) antibody overnight at $4^{\circ} \mathrm{C}$. Protein $\mathrm{G}$ sepharose beads (50 $\mu 1$, Sigma) were added for $2 \mathrm{~h}$. After discarding the supernatant, the beads were washed three times with a RIPA buffer. The samples were separated and analyzed by $6 \%$ SDS-PAGE and then transferred to PVDF membranes. The blots were probed with the monoclonal anti-phosphotyrosine antibody (4G10; Upstate, Charlottesville, VA) and visualized using an ECL system. The blots were stripped and reprobed with the polyclonal antibody for DDR1 (C-20).

Migration assay. The migration assays were assessed using a 48 -well microchemotaxis chamber with an $8-\mu \mathrm{m}$ pore size (Neuroprobe Inc., Gaithersburg, MD). Cells $\left(2.5 \times 10^{4}\right)$ overexpressing DDR1a, DDR1b and vector alone (mock) were suspended in DMEM and placed in the upper chambers. The upper and lower chambers were separated by a polyvinylpyrrolidone-free polycarbonate membrane, of which one group was coated with collagen type I $(0.2 \mathrm{mg} / \mathrm{ml}$, Sigma) (Group 1) and the other group had no coating (Group 2). DMEM containing 5\% FBS was placed as a source of chemoattractant in the lower chamber in Group 1, whereas collagen type I $(0.3 \mathrm{mg} / \mathrm{ml})$ was placed in Group 2. After a 12-h incubation, the cells on the upper surface of the filter were wiped with a cotton swab. The cells on the lower surface of the filters were fixed and stained for 10 min with a Diff-Quik solution (Dade Behring, Deerfield, IL). For each replicate, the HCC cells that had migrated to the lower surface of the filter were counted by an optical microscope in six randomly selected fields (x200) per well. 
A

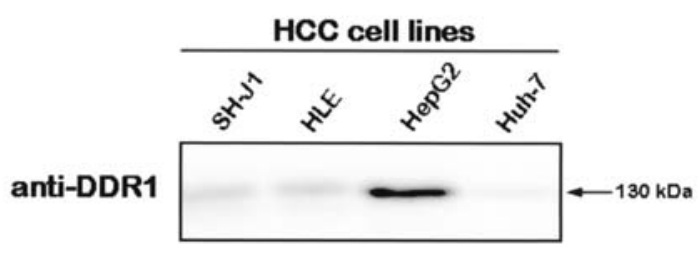

B

HLE Huh-7

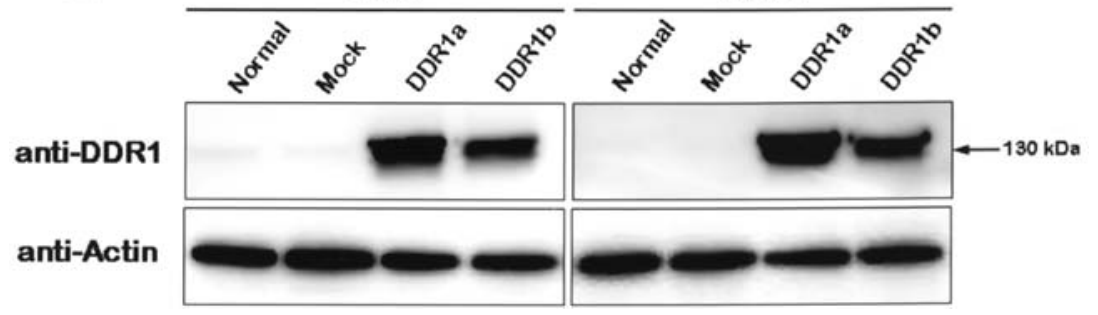

Figure 1. (A) Expression of DDR1 in the four HCC cell lines. In the Western blot, a low level of expression band was identified in three HCC cell lines including HLE, Huh-7 and SH-J1, whereas a moderate expression level was observed in HepG2. (B) Expression of DDR1 after transfection with DDR1a or DDR1b in the HLE and Huh-7 cell lines. The transiently transfected HLE and Huh-7 cells overexpressed the DDR1 protein.

Invasion assay. The invasion assays were performed using a 24-transwell BD BioCoat matrigel invasion chamber with an $8 \mu \mathrm{m}$ pore size (BD Biosciences, San Jose, CA). Human collagen type I $(0.3 \mathrm{mg} / \mathrm{ml}$, Sigma $)$ in DMEM plus $1 \%$ FBS was placed in the lower chambers. Cells $\left(5 \times 10^{4}\right)$ overexpressing DDR1a, DDR1b and the vector alone (mock) in DMEM plus $0.5 \%$ FBS were placed in the upper chambers in triplicate. The cells were allowed to invade through the matrigel at $37^{\circ} \mathrm{C}$ for $22 \mathrm{~h}$ and were stained with a Diff-Quik solution. For each replicate, the HCC cells that had migrated to the lower surface of the filter were counted using an optical microscope in six randomly selected fields (x100) per well.

Zymography. The conditioned medium from the Huh-7 and HLE cell lines was stimulated with collagen type $\mathrm{I}(30 \mu \mathrm{g} / \mathrm{ml})$ and collected after $16 \mathrm{~h}$. The conditioned medium (20 $\mu \mathrm{l})$ was mixed with $5 \mu \mathrm{l}$ of an SDS sample buffer and left to stand at room temperature for $10 \mathrm{~min}$. The mixtures were electrophoresed on $7.5 \%$ PAGE containing $1 \mathrm{mg} / \mathrm{ml}$ gelatin (Sigma). After electrophoresis, the gels were washed twice for $30 \mathrm{~min}$ with $2.5 \%$ Triton $\mathrm{X}-100$ and incubated overnight at $37^{\circ} \mathrm{C}$ in the developing buffer (50 mM Tris- $\mathrm{HCl}, 200 \mathrm{mM} \mathrm{NaCl}, 5 \mathrm{mM}$ $\mathrm{CaCl}_{2}, 0.02 \%$ Brij 35, pH 7.5). The gels were then stained for 30 min with $30 \%$ methanol $/ 10 \%$ acetic acid containing $0.5 \%$ Coomassie brilliant blue R-250 and destained in the same solution without dye. The clear bands on the blue background represent the areas of gelatinolysis. The digestion bands were quantified using an LAS-3000 image analyzer system (Fuji Photo Film).

Statistical analysis. The t-test was used to determine the statistical significance of the data and compare the means of the two groups. The one-way ANOVA test was used for multiple comparisons. $\mathrm{P}<0.05$ was considered significant.

\section{Results}

DDRl is expressed in HCC cells in culture. The expression level of the DDR1 protein in the four HCC cell lines was determined by Western blotting using an anti-DDR 1 antibody. A low level of expression was detected in the three HCC cell lines including HLE, Huh-7 and SH-J1, whereas a moderate level of expression was found in HepG2 (Fig. 1A). A band of $130 \mathrm{kDa}$ corresponding to the DDR1a and DDR1b isoforms was detected using the polyclonal antibody at the C-terminal domain of DDR1. As the level of DDR1 expression in the HLE and Huh-7 cells was weak, the two cell lines were transfected with DDR1 to determine the effects of DDR1 on migration and invasion in the HCC cell lines.

In order to examine the role of DDR1 in HCC progression, an HCC cell line model was developed by transiently transfecting the HLE and Huh-7 cells with DDR1a and DDR1b cDNA in a plasmid vector. These cells were lysed and probed with the anti-DDR1 C-terminal antibody. As shown in Fig. 1B, the transfection was satisfactory and the DDR1 protein was overexpressed by the transfected HLE and Huh-7 cells.

DDR1 is activated and tyrosine-phosphorylated by collagen type I in HCC cells. The levels of tyrosine phosphorylation of the DDR1 receptor were measured by immunoprecipitation with the DDR1 antibody, which was followed by immunoblot analysis using the 4G10 phosphotyrosine antibody. As shown in Fig. 2, the phosphorylation of DDR1 was identified in the DDR1-overexpressing HLE and Huh-7 cells incubated in the collagen type I $(30 \mu \mathrm{g} / \mathrm{ml})$-coated dish. This suggests that collagen type I can induce the activation of the DDR1 by the tyrosine phosphorylation of its intracellular domain.

Overexpression of DDRIa and DDRIb stimulates HCC cell migration and invasion in vitro. In the migration assay, the average number of migrating cells in the collagen type Icoated group (Group 1) was 3 times higher in the HLE cells (Fig. 3A, Table I) and 2 times higher in the Huh-7 cells (Fig. 3B, Table I) compared with the non-coated group (Group 2). This suggests that collagen type I stimulates DDR1 into increasing the level of migration of the transfected HCC cells. In Group 1, the number of migrating HLE cells were 


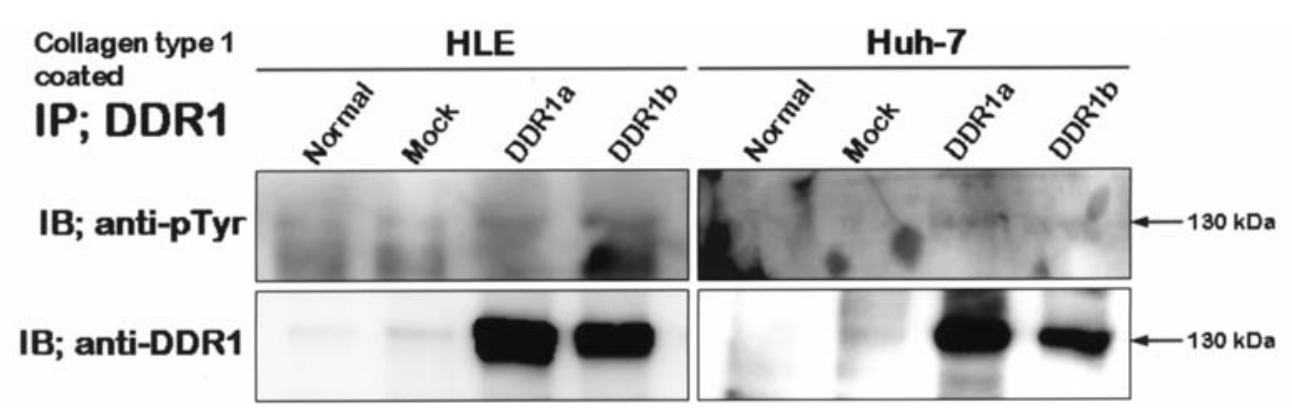

Figure 2. Immunoprecipitation for the DDR1 phosphorylation of the HLE and Huh-7 cells. After stimulation with collagen type I (30 $\mu \mathrm{g} / \mathrm{ml})$, DDR1 was tyrosine-phosphorylated in the transfected HLE and Huh-7 cells.
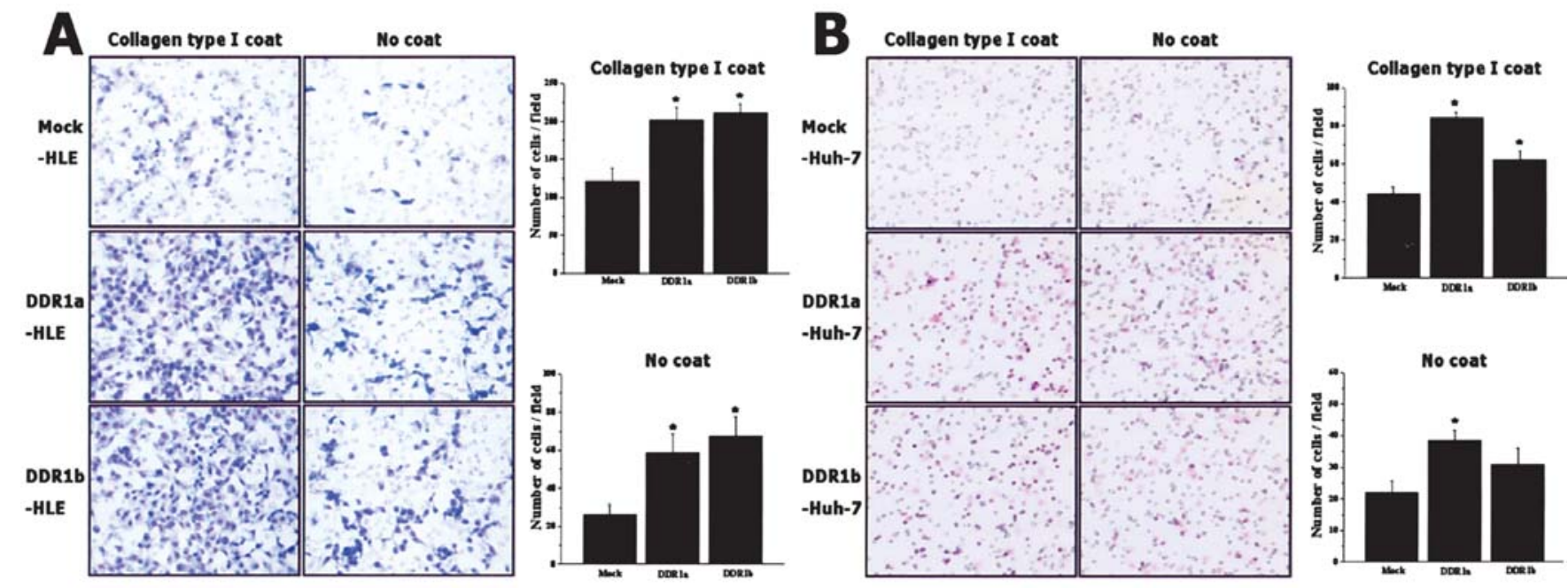

Figure 3. (A) Migration assay for the DDR1a- or DDR1b-overexpressing HLE cells. The average number of migrating cells in the collagen type I-coated group (Group 1) was higher than the non-coated group (Group 2). In Groups 1 and 2, DDR1a or DDR1b overexpression resulted in a significant increase in the number of migrating cells compared with the control. (B) Migration assay for the DDR1a- or DDR1b-overexpressing Huh-7 cells. The average number of migrating cells in Group 1 was higher than in Group 2. DDR1a or DDR1b overexpression results in a significant increase in the number of migrating cells compared with the control, except for the DDR1b-overexpressing Huh-7 cells in Group 2. ${ }^{*} \mathrm{P}<0.01$.

Table I. Correlation between the number of migrating cells and the overexpression of DDR1a or DDR1b in HLE and Huh-7 cells.

\begin{tabular}{llcccc}
\hline Collagen type I & & $\begin{array}{c}\text { HLE } \\
(\text { mean } \pm \text { SE) }\end{array}$ & P-value & $\begin{array}{c}\text { Huh-7 } \\
(\text { mean } \pm \text { SE) }\end{array}$ & P-value $^{\mathrm{a}}$ \\
\hline Coated group & Mock & $121.5 \pm 17.08$ & & $44.2 \pm 3.89$ & \\
(Group 1) & DDR1a & $202.8 \pm 16.03$ & 0.0088500 & $84.0 \pm 3.34$ & 0.0000012 \\
& DDR1b & $210.9 \pm 12.34$ & 0.0024500 & $62.2 \pm 4.80$ & 0.0041300 \\
Non-coated & Mock & $25.8 \pm 5.630$ & & $22.0 \pm 3.76$ & \\
group (Group 2) & DDR1a & $58.7 \pm 9.690$ & 0.0037600 & $38.5 \pm 3.36$ & 0.0034900 \\
& DDR1b & $67.3 \pm 10.36$ & 0.0000082 & $30.8 \pm 5.36$ & 0.1913600 \\
\hline
\end{tabular}

${ }^{\mathrm{a}}$ t-test; SE, standard error.

1.6 and 1.7 times higher after DDR $1 \mathrm{a}$ and DDR $1 \mathrm{~b}$ overexpression than the control HLE cells, respectively $(\mathrm{P}<0.01)$. The number of migrating Huh-7 cells was 1.9 and 1.3 times higher after DDR1a and DDR1b overexpression than the control Huh-7 cells, respectively $(\mathrm{P}<0.01)$. In Group 2 , the number of migrating HLE cells was 2.3 and 2.6 times higher after DDR1a and DDR1b overexpression than the control HLE cells, respectively $(\mathrm{P}<0.01)$. The number of 


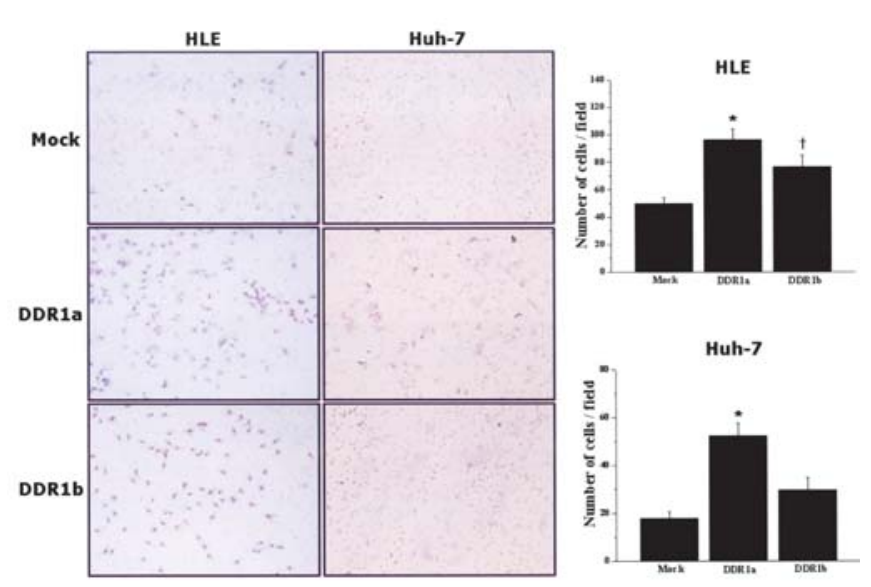

Figure 4. Invasion assay for the DDR1a- or DDR1b-overexpressing HLE and Huh-7 cells. In the HLE cells, DDR1a or DDR1b overexpression resulted in a significant increase in invasion compared with the control cells. In the Huh-7 cells, DDR1a overexpression resulted in a significant increase in invasion compared with the control. ${ }^{*} \mathrm{P}<0.01,{ }^{\dagger} \mathrm{P}<0.05$. migrating Huh-7 cells was 1.7 times higher after DDR1a overexpression than the control Huh-7 cells $(\mathrm{P}<0.01)$. There was a tendency for an increase in the number of migrating Huh-7 cells to occur after DDR1b overexpression but this was not significant.

In the invasion assay, the number of invading HLE cells was 1.9 and 1.5 times higher after DDR1a and DDR1b overexpression than the control HLE cells, respectively (Fig. 4, Table II) $(\mathrm{P}<0.05)$. The number of invading Huh-7 cells was 3 times higher after DDR1a overexpression than the control Huh-7 cells $(\mathrm{P}<0.01)$. There was a tendency for an increase in the number of invading Huh-7 cells to occur after DDR1b overexpression but this was not significant.

Increased invasion in DDRla- and DDRIb-overexpressing $H C C$ cells is associated with MMP. Zymography was used to determine if the invasion of DDR1-overexpressing cells was mediated by the activation of MMP-2 and -9 (Fig. 5). In the HLE cells, DDR1a and DDR1b overexpression resulted in a significant increase in the expression of MMP-2 and -9 . Moreover, the active form of MMP-2 was also higher in the DDR1a- and DDR1b-overexpressing cells. In the Huh-7 cells,

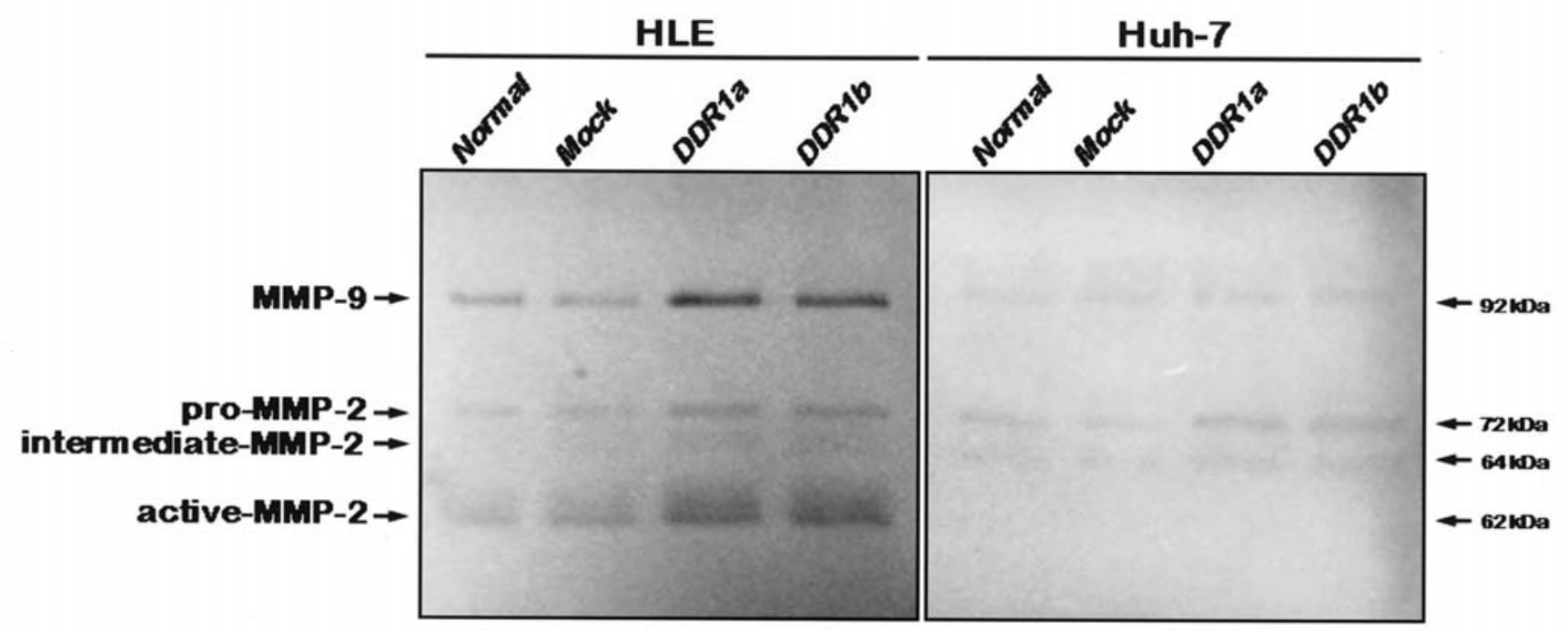

Figure 5. Zymography for DDR1a- or DDR1b-overexpressing HLE and Huh-7 cells. Expression of MMP-9 was higher in the DDR1a- and DDR1boverexpressing HLE and Huh-7 cells than in the control. In HLE cells, the active form of MMP-2 was also increased after the overexpression of DDR1a and DDR1b. In the Huh-7 cells, the band for the active form of MMP-2 was unclear.

Table II. Correlation between the number of invading cells and the overexpression of DDR1a or DDR1b in HLE and Huh-7 cells.

\begin{tabular}{lcccc}
\hline & $\begin{array}{c}\text { HLE } \\
(\text { mean } \pm \text { SE) }\end{array}$ & P-value & $\begin{array}{c}\text { Huh-7 } \\
(\text { mean } \pm \text { SE })\end{array}$ & P-value $^{\mathrm{a}}$ \\
\hline Mock & $49.8 \pm 4.33$ & & $17.8 \pm 2.85$ & 0.000003 \\
DDR1a & $96.6 \pm 7.90$ & 0.000006 & $52.3 \pm 5.36$ & 0.068310 \\
DDR1b & $76.3 \pm 8.75$ & 0.014180 & $29.6 \pm 5.31$ & \\
\hline
\end{tabular}

at-test; SE, standard error 
DDR1a and DDR1b overexpression produced a slight increase in the MMP-2 and -9 expression. The band for the active form of MMP-2 was unclear.

\section{Discussion}

HCC is one of the most common solid tumors worldwide with a poor prognosis (1) because it quickly permeates the liver through the portal venous system, to spread first within the liver itself and then to other organs including the diaphragm, regional lymph nodes, biliary tree and the lung (21). The ability of HCC cells to invade is a major factor accounting for the high mortality and morbidity of the disease. A major cause of the high mortality is the inability to excise all tumor cells surgically. Therefore, new treatments that suppress the invasiveness of HCC should improve the prognosis of patients with HCC.

During the search for tyrosine kinase proteins expressed in human malignancies, DDR, a novel subfamily of RTK, was discovered. DDR is distinguished from other RTKs by a discoidin domain in their extracellular domain, which is important for the regulation of cell spreading and morphogenesis (22). The two members of this family, DDR1 and DDR2, are both characterized by a 155 -amino acid discoidin homology domain in the extracellular region of the protein. This domain is followed by a 200 -amino acid stretch known as the stalk region, a single transmembrane, a juxtamembrane region and the catalytic tyrosine kinase domain. DDR1, which was previously called DDR, NEP, Cak, Ptk-3, MCK-10, RTK6, EDDR1, or NTRK4 (3,7,8,23-28), appears in five isoforms: $\mathrm{a}, \mathrm{b}, \mathrm{c}, \mathrm{d}$ and e, which are generated by alternative splicing (4,5). Exon 11, which encodes an additional 37 amino acids in the juxtamembrane region, is missing in the transcript of DDR1a but is present in DDR1b. Another 6 amino acids were inserted at the beginning of the kinase domain to give rise to the c-isoform. DDR1d and DDR1e are additional splice variants within the juxtamembrane region. DDR1 is activated by collagen types I to $\mathrm{V}$, whereas DDR2 is selectively stimulated by the fibrillar collagens only (12).

Collagen plays an important role during wound healing and adult tissue because it is a major ECM protein, providing tensile strength and support and its presence modulates various cell functions. The interaction between collagen and the DDRs leads to a wide variety of outcomes. Regarding wound healing, changing the collagen levels appears to act as a stimulus for the DDR within the fibroblasts, keratinocytes, macrophages and smooth muscle cells and as a measure of the status of ECM remodeling and maturation (29). The interaction between collagen and the DDR is a key proof of the principle that ECM can serve as a ligand for receptor tyrosine kinases (12). Our results highlight its role as a ligand for DDR1 because the number of migrating cells was significantly higher in the collagen type I-coated group than in the noncoated group.

In general, ligand binding to RTKs is believed to induce receptor dimerization and the subsequent transphosphorylation of the specific tyrosine residues in the cytoplasmic domain, evident in the results, shows that collagen type I binding with DDR1 induces the phosphorylation of the cytoplasmic tyrosine residue. This follows the binding of the downstream effector molecules containing Src-homology 2 (SH2) or the phosphotyrosine-binding (PTB) domain (30). Regarding the signal pathway of DDR1, there are several reports of chemokine production through the p38 MAP kinase and NF- $\mathrm{kB}$ pathway in human macrophages (31) and p53-mediated cell survival via the Ras/raf/MAPK cascade (32). However, the pathways through which DDR1 plays a role in migration and invasion are not completely understood.

The effects of DDR 1 in cell migration in different cell models are controversial. A disruption of the DDR1 gene in mice results in viable animals that are significantly smaller than their littermates, while female DDR1-null mice showed defects in blastocyst implantation and mammary gland development (6). Primary vascular smooth muscle cells isolated from the DDR1-null mice showed decreased proliferation, collagen attachment and migration in vitro (33). In contrast, the primary mesangial cells isolated from the kidney of the same mice showed enhanced proliferation (34). These observations suggest that DDR1 is associated with cell attachment, migration and proliferation. Furthermore, DDRs play an important role in regulating the assembly and differentiation of neurons, mammary cells and myoblasts in vitro, which are processes that involve coordinated interactions with the matrix during the proliferation, migration and extension of cellular protrusions (35-37).

Besides its role in normal tissues, the overexpression of DDR1 suggests a function in tumor progression in several human cancers. High levels of DDR1 were reported in invasive tumors of the breast, ovary, esophagus and lung $(3,5-8,23)$. Although DDR1 was previously identified in human tumor tissues, our results provide evidence that HCC cells overexpress DDR1. This study addressed whether or not DDR1overexpressing HCC cells could increase their rate of migration and invasion. This report provides evidence that the overexpression of DDR1a or DDR1b can induce HCC cell migration and invasion in vitro. Although the number of migrating cells in the DDR1b-overexpressing Huh-7 cells did not increase significantly, there was a tendency for increased migration and invasion to occur compared with the control cells. These results are similar to those reported by Kamohara et al (38), who proposed an interaction between DDR1a and collagen in leukocyte migration. However, there is a report on the different roles of DDR $1 \mathrm{a}$ and DDR $1 \mathrm{~b}$ in migration and invasion in the glioma cell line (10). One reason for these differences may be the divergent signaling events.

MMPs can degrade the ECM components, which is a key step in tumor invasion and metastasis. This study examined MMP-2 and -9 to determine if they are associated with invasion in DDR1a- and DDR1b-overexpressing HCC cells. These results demonstrated that the expression of MMP-2 and -9 was higher in the DDR1a- and DDR1b-overexpressing HLE and Huh-7 cells. More importantly, the active form of MMP-2 is higher in the DDR1a- and DDR1b-overexpressing HLE but not in the Huh-7 cells. These results suggest that the increased ability of the DDR1a- and DDR1b-overexpressing HCC cells to migrate and invade is mediated by MMP, particularly the activated MMP-2 in HLE cells.

This study provides evidence that DDR1 is present in the HCC cell lines and the overexpression of either DDR1a or 
DDR1b enhances migration, particularly after collagen type I stimulation and the invasion of HLE and Huh-7 cells. In addition, the effect of DDR1a and DDR $1 b$ on invasion is associated with MMP-2 and -9. Although this study provided one possible mechanism for the invasion of HCC cells, more studies are needed to understand the signal through which DDR1a and DDR1b play their role in invasion.

\section{Acknowledgements}

This study was supported by a grant from the Korea Science and Engineering Foundation (R01-2005-000-10942-0).

\section{References}

1. Parkin DM, Bray F, Ferlay J and Pisani P: Global cancer statistics, 2002. CA Cancer J Clin 55: 74-108, 2005.

2. EL-Serag HB, Mason AC and Key C: Trends in the survival of patients with hepatocellular carcinoma between 1977 and 1996 in the United States. Hepatology 33: 62-65, 2001.

3. Alves F, Vogel W, Mossie K, Millauer B, Hofler H and Ullrich A: Distinct structural characteristics of discoidin I subfamily receptor tyrosine kinases and complementary expression in human cancer. Oncogene 10: 609-618, 1995.

4. Vogel W: Discoidin domain receptors: structural relations and functional implications. FASEB J 13: S77-S82, 1999.

5. Alves F, Saupe S, Ledwon M, Schaub F, Hiddemann W and Vogel WF: Identification of two novel, kinase-deficient variants of discoidin domain receptor 1: differential expression in human colon cancer cell lines. FASEB J 15: 1321-1323, 2001.

6. Vogel WF, Aszodi A, Alves F and Pawson T: Discoidin domain receptor 1 tyrosine kinase has an essential role in mammary gland development. Mol Cell Biol 21: 2906-2917, 2001.

7. Johnson JD, Edman JC and Rutter WJ: A receptor tyrosine kinase found in breast carcinoma cells has an extracellular discoidin I-like domain. Proc Natl Acad Sci USA 90: 5677-5681, 1993.

8. Laval S, Butler R, Sheling AN, Handby AW, Poulsom R and Ganesan TS: Isolation and characterization of an epithelialspecific receptor tyrosine kinase from an ovarian cancer cell line. Cell Growth Differ 5: 1173-1183, 1994.

9. Nemoto T, Ohashi K, Akashi T, Johnson JD and Hirokawa K: Overexpression of protein tyrosine kinases in human esophageal cancer. Pathobiology 65: 165-203, 1997.

10. Ram R, Lorente G, Nikolich K, Urfer R, Foehr E and Nagavarapu U: Discoidin domain receptor-1a (DDR 1a) promotes glioma cell invasion and adhesion in association with matrix metalloproteinase-2. J Neurooncol 76: 239-248, 2006.

11. Shrivastave A, Radziejewski C, Campbell E, et al: An orphan receptor tyrosine kinase family whose members serve as nonintegrin collagen receptors. Mol Cell 1: 25-34, 1997.

12. Vogel W, Gish G, Alves F and Pawson T: The discoidin domain receptor tyrosine kinases are activated by collagen. Mol Cell 1: 13-23, 1997.

13. Edwards DR and Murphy G: Proteases-invasion and more. Nature 394: 527-528, 1998.

14. Yoshimoto M, Itoh $\mathrm{F}$, Yamamoto $\mathrm{H}$, Hinoda $\mathrm{Y}$, Imai $\mathrm{K}$ and Yachi A: Expression of MMP-7 (Pump-1) mRNA in human colorectal cancers. Int J Cancer 54: 614-618, 1993.

15. Senota A, Itoh F, Yamamoto H, Adachi Y, Hinoda $Y$ and Imai K: Relation of matrilysin messenger RNA expression with invasive activity in human gastric cancer. Clin Exp Metastasis 16: 313-321, 1998.

16. Uhm JH, Dooley NP, Villemure JG and Yong VW: Glioma invasion in vitro: regulation by matrix metalloprotease- 2 and protein kinase C. Clin Exp Metastasis 14: 421-433, 1996.

17. Giannelli G, Bergamini C, Marinosci F, et al: Clinical role of MMP-2/TIMP-2 imbalance in hepatocellular carcinoma. Int J Cancer 97: 425-431, 2002.

18. Sakamoto Y, Mafune K, Mori M, et al: Overexpression of MMP-9 correlates with growth of small hepatocellular carcinoma. Int J Oncol 17: 237-243, 2000.
19. Arri S, Mise M, Harada T, et al: Overexpression of matrix metalloproteinase 9 gene in hepatocellular carcinoma with invasive potential. Hepatology 24: 316-322, 1996.

20. Kim DG, Park SY, Kim H, Chun YH, Moon WS and Park SH: A comprehensive karyotypic analysis on a newly established sarcomatoid hepatocellular carcinoma cell line SH-J1 by comparative genomic hybridization and chromosome painting. Cancer Genet Cytogenet 132: 120-124, 2002.

21. Kondo Y and Wada K: Intrahepatic metastasis of hepatocellular carcinoma. A histopathologic study. Hum Pathol 22: 125-130, 1991.

22. Springer WR, Cooper DN and Barondes SH: Discoidin I is implicated in cell-substratum attachment and ordered cell migration of Dictyostelium discoideum and resembles fibronectin. Cell 39: 557-564, 1984.

23. Zerlin M, Julius MA and Goldfarb M: NEP: a novel receptor-like tyrosine kinase expressed in proliferative neuroepithelia. Oncogene 8: 2731-2739, 1993.

24. Perez JL, Shen X, Finkernagel S, et al: Identification and chromosomal mapping of a receptor tyrosine kinase with putative phospholipids binding sequence in its ectodomain. Oncogene 9: 211-219, 1994.

25. Di Marco E, Cutuli N, Guerra L, Cancedda R and De Luca M: Molecular cloning of trkE, a novel trk-related putative tyrosine kinase receptor isolated from normal human keratinocytes and widely expressed by normal human tissues. J Biol Chem 268: 24290-24295, 1993.

26. Shelling AN, Butler R, Jones T, Laval S, Boyle JM and Ganesan TS: Localization of an epithelial-specific receptor (EDDR1) to chromosome 6q16. Genomics 25: 584-587, 1995.

27. Valent A, Meddeb M, Danglot G, Duverger A, Nguyen VC and Bernheim A: Assignment of the NTRK4 (trkE) gene to chromosome 6p21. Human Genet 98: 12-15, 1996.

28. Sanchez MP, Tapley P, Saini SS, He B, Pulido D and Barbacid M: Multiple tyrosine protein kinases in rat hippocampal neurons: isolation of Ptk-3, a receptor expressed in proliferative zones of the developing brain. Proc Natl Acad Sci USA 91: 1819-1823, 1994.

29. Tran KT, Griffith L and Wells A: Extracellular matrix signaling through growth factor receptors during wound healing. Wound Repair Regen 12: 262-268, 2004

30. Pawson T and Scott JD: Signaling through scaffold, anchoring and adaptor proteins. Science 278: 2075-2080, 1997.

31. Matsuyama W, Wang L, Farrar WL, Faure M and Yoshimura T: Activation of discoidin domain receptor 1 isoform $b$ with collagen up-regulates chemokine production in human macrophages: role of $\mathrm{p} 38$ mitogen-activated protein kinase and NF-кB. J Immunol 172: 2332-2340, 2004.

32. Ongusaha PP, Kim JI, Fang L, et al: p53 induction and activation of DDR1 kinase counteract p53-mediated apoptosis and influence p53 regulation through a positive feedback loop. EMBO J 22: 1289-1301, 2003.

33. Hou G, Vogel WF and Bendeck MP: Tyrosine kinase activity of discoidin domain receptor 1 is necessary for smooth muscle cell migration and matrix metalloproteinase expression. Circ Res 90: 1147-1149, 2002

34. Wang CZ, Hsu YM and Tang MJ: Function of discoidin domain receptor 1 in HGF-induced branching tubulogenesis of MDCK cells in collagen gel. J Cell Physiol 203: 295-304, 2005.

35. Vogel W, Brakebusch C, Fassler R, Alves F, Ruggerio F and Pawson T: Discoidin domain receptor 1 is activated independently of $\beta_{1}$ integrin. J Biol Chem 275: 5779-5784, 2000.

36. Bhatt RS, Tomada T, Fang Y and Hatten ME: Discoidin domain receptor 1 functions in axon extension of cerebellar granule neurons. Genes Dev 14: 2216-2228, 2000.

37. Jonsson $M$ and Andersson T: Repression of Wnt-5a impairs DDR1 phosphorylation and modifies adhesion and migration of mammary cells. J Cell Sci 114: 2043-2053, 2001.

38. Kamohara H, Yamashiro S, Galligan C and Yoshimura T: Discoidin domain receptor 1 isoform-a (DDR1a) promotes migration of leukocytes in three-dimensional collagen lattices. FASEB J 15: 2724-2726, 2001. 